\title{
Atividade alelopática de extratos de diferentes partes de juazeiro (Ziziphus joazeiro Mart. - Rhamnaceae)
}

\author{
Andreya Kalyana de Oliveira ${ }^{1}$, Maria de Fátima Barbosa Coelho ${ }^{2,4}$, \\ Sandra Sely Silveira Maia ${ }^{1}$, Francisco Ésio Porto Diógenes ${ }^{1}$ e Sebastião Medeiros Filho ${ }^{3}$
}

Recebido em 29/01/2011. Aceito em 14/06/2012

\begin{abstract}
RESUMO
(Atividade alelopática de extratos de diferentes partes de juazeiro (Ziziphus joazeiro Mart. - Rhamnaceae). O objetivo neste trabalho foi avaliar o potencial alelopático do extrato de cascas e de folhas juazeiro (Ziziphus joazeiro Mart.) sobre as sementes de alface (Lactuca sativa L.). Foram conduzidos dois experimentos, em ambos foi usado o delineamento inteiramente casualizado. No primeiro foram realizadas quatro repetições e cinco tratamentos (EF - extrato de folhas a $100{ }^{\circ} \mathrm{C}, \mathrm{EF}$ - extrato de folhas a $25^{\circ} \mathrm{C}, \mathrm{EC}$ - extrato de cascas a $100{ }^{\circ} \mathrm{C}$, EC - extrato de cascas a $25{ }^{\circ} \mathrm{C}$, e água destilada). No segundo foram realizados cinco tratamentos $(0 \%, 25 \%, 50 \%, 75 \%$ e $100 \%$ de concentração do extrato bruto) e quatro repetições com 20 sementes de alface. O extrato bruto foi obtido após a agitação das cascas e das folhas com água em liquidificador utilizando-se $50 \mathrm{~g}$ de material para $500 \mathrm{ml}$ de água. Os resultados mostraram efeito do extrato dependendo da concentração. Os extratos brutos e diluídos de Z. joazeiro não afetaram a germinação, mas nas maiores concentrações causaram elevada porcentagem de plântulas anormais e o extrato de folhas e de cascas extraído a $100^{\circ} \mathrm{C}$ reduziram o crescimento da raiz e parte aérea. Extratos aquosos de cascas e de folhas de Z. juazeiro apresentam efeito fitotóxico na germinação de sementes de L. sativa.
\end{abstract}

Palavras-chave: germinação, extratos de cascas, extrato de folhas, alface

\begin{abstract}
(Allelopathic activity of different parts of juazeiro (Ziziphus joazeiro Mart. - Rhamnaceae)). This study aimed to identify the allelopathic activity of extracts from Ziziphus joazeiro bark and leaves on the seeds of lettuce (Lactuca sativa). Two experiments were conducted, which both used a randomized design. The first four replicates were the following treatments (EF-extract of leaves at $100^{\circ} \mathrm{C}, \mathrm{EF}$-extract of leaves at $25^{\circ} \mathrm{C}, \mathrm{EC}$-extract of bark at $100^{\circ} \mathrm{C}, \mathrm{EC}$-extract of bark at $25^{\circ} \mathrm{C}$, and distilled water). The next five treatments used $0 \%, 25 \%, 50 \%, 75 \%$ and $100 \%$ concentrations of the crude extract and four replicates of 20 seeds. The crude extract was obtained after the bark and leaves were blended with water ( $50 \mathrm{~g}$ of material for $500 \mathrm{ml}$ of water). The results showed that the effect of the extract depended on the concentration. The crude and diluted extracts did not affect germination, but in higher concentrations the extracts caused an high percentage of abnormal seedlings and the extracts of the leaves and bark produced at $100^{\circ} \mathrm{C}$ reduced root and shoot growth. Aqueous extracts of bark and leaves of $Z$. juazeiro have a toxic effect on seed germination of $L$. sativa.
\end{abstract}

Key words: germination, stem bark extracts, leave extracts, lettuce

\section{Introdução}

A alelopatia é definida como a interferência positiva ou negativa de compostos do metabolismo secundário produzidos por uma planta (aleloquímicos) que lançados no meio causam interferência sobre o desenvolvimento de outra planta de forma direta ou indireta, por meio da transformação dessas substâncias no solo ou pela atividade de microorganismos (Ferreira \& Borghetti 2004). Desta forma, se aceita a alelopatia como ciência abrangente, que poderá ter um papel importante no controle de plantas daninhas que afetam culturas agrícolas, na condução de sistemas agroflorestais e agrosilvopastoris.

Existem inúmeros trabalhos científicos que comprovam a alelopatia em espécies vegetais. Nesse sentido Leite \& Oliveira

\footnotetext{
${ }^{1}$ Universidade Federal Rural do Semi Árido, Programa de Pós-Graduação em Fitotecnia, Mossoró, RN, Brasil

${ }^{2}$ Universidade da Integração Internacional da Lusofonia Afro Brasileira, Área de Desenvolvimento Rural, Redenção, CE, Brasil

${ }^{3}$ Universidade Federal do Ceará, Centro de Ciências Agrárias, Departamento de Fitotecnia, Laboratório de Análise de Sementes, Fortaleza, CE, Brasil

${ }^{4}$ Autor para correspondência: coelhomfstrela@gmail.com
} 
(2007) apontam os extratos de folhas jovens Solanum lycocarpum a 5\% e 3\% como inibidor do crescimento radicular da Sesamum indicum L. Já em bioensaio realizado por Souza et al. (2005) foi observada atividade alelopática e citotóxica dos extratos aquosos de espinheira-santa (Maytenus ilicifolia Mart.) sobre sementes de alface (Lactuca sativa L.). Enquanto, Mazzafera (2003) utilizou extratos etanólicos de cravo da índia (Eugenia caryophyllata Thunb) sobre sementes de rabanete (Raphanus sativus L.), tomate (Lycopersicon esculentum), trigo (Triticum aestivum L.), alface (Lactuca sativa L.), Impatiens balsamina e Crotalaria spectabilis, para comprovar efeitos alelopáticos desses extratos.

Entretanto, as espécies nativas da caatinga, um dos biomas mais ameaçados do Brasil, têm sido pouco estudadas. Uma das espécies promissoras da caatinga é o juazeiro (Ziziphus joazeiro Mart.) que tem o uso em xampus devido a presença de saponinas em várias partes da planta, substâncias reconhecidas com efeito alelopático em vários estudos (Maraschin-Silva \& Áquila 2005; Maraschin-Silva \& Áquila 2006; Gusman et al. 2008).

Z. joazeiro ocorre desde o nordeste até o norte de Minas Gerais (Lorenzi 2009). Apresenta grande importância econômica e ecológica, sendo utilizada localmente para produção de lenha e carvão, arborização de ruas e jardins, além de possuir frutos comestíveis, os quais são explorados de forma extrativista (Lorenzi 2009). É empregado na fabricação de sabão, dentifrício e na indústria madeireira (Lorenzi \& Matos 2008). Também é uma das espécies do bioma caatinga bastante utilizada na medicina popular como expectorante, no tratamento de bronquites e de ulceras gástricas, na fabricação de cosméticos e creme dental, além de servir na alimentação de animais principalmente nos períodos de seca (Lorenzi 2009).

Em estudo realizado com a espécie, Oliveira et al. (2009) verificaram que as maiores concentrações do extrato (100, 75 e $50 \%$ ) da polpa dos frutos $Z$. joazeiro apresentaram efeito alelopático desfavorável sobre a germinação de alface, reduzindo-a em 100, 98,75 e 82,5\%. O extrato das cascas dos frutos nas concentrações de $75 \%$ e $100 \%$ reduziu a germinação da alface em $28,75 \%$ e $78,75 \%$. Sendo assim, é possível que outras partes da planta apresentem efeito alelopático e o presente estudo teve o objetivo de avaliar o potencial alelopático de extratos de cascas e de folhas de $Z$. joazeiro obtidos a temperatura de 25 e $100{ }^{\circ} \mathrm{C}$ e em diversas concentrações.

\section{Material e métodos}

Foram utilizadas cascas do caule e folhas adultas de juazeiro coletadas no campus da Universidade Federal Rural do Semi Arido (UFERSA) na cidade de Mossoró - RN e sementes de alface da cultivar "Mônica SF FI", com percentual de germinação acima de $90 \%$, adquiridas comercialmente na cidade de Mossoró-RN.

O material utilizado na confecção dos extratos foi coletado no final da tarde e levado ao Laboratório de Análise de Sementes (LAS), onde ficou acondicionado em sacola de papel sob condição ambiente. No dia seguinte foram pesadas em balança de precisão duas porções de $50 \mathrm{~g}$ de cada órgão e colocadas durante $5 \mathrm{~min}$ em recipientes contendo uma solução de $10 \mathrm{~mL}$ de hipoclorito de sódio $(2,0$ a 2,5\% p/p de cloro ativo) diluído em $500 \mathrm{~mL}$ de água destilada. Depois foram lavadas em água corrente e secas com papel toalha. As duas porções de folhas e as duas de cascas foram colocadas separadamente em béqueres, para receber os tratamentos. $\mathrm{Na}$ extração a quente colocou-se em cada recipiente $500 \mathrm{~mL}$ de água destilada a temperatura de $100^{\circ} \mathrm{C}$ e na extração a frio seguiu-se o mesmo procedimento, sendo que a temperatura da água adicionada foi de $25^{\circ} \mathrm{C}$. O tempo de extração do material foi de $30 \mathrm{~min}$. Logo após, cada conteúdo dos recipientes foi submetido à trituração durante um minuto em liquidificador doméstico. Cada material triturado passou por um processo de filtragem em pano tipo perfex, ficando retida toda parte fibrosa.

Depois, o material filtrado correspondente a cada extrato foi colocado em recipientes plásticos e feito a análise físico-químico do mesmo, uma vez que o potencial osmótico e o elevado grau de acidez ou basicidade dos extratos podem mascarar o fenômeno alelopático (Ferreira \& Aquila 2000). A determinação do $\mathrm{pH}$ foi feita com um pHmetro de bancada (modelo S20K, marca Mettler Toledo) e a condutividade elétrica $(\mathrm{CE})$ foi medida pelo condutivímetro portátil (modelo SG3- ELK, marca Mettler Toledo). A partir dos valores da CE determinou-se o potencial osmótico $(\mathrm{PO})$ de acordo com a fórmula proposta por Ayers \& Westcot (1994): Potencial osmótico em atmosfera (ATM) $=-0,36 x$ CE. Os dados foram transformados para (Mpa).

No primeiro experimento o delineamento experimental foi inteiramente casualizado com cinco tratamentos (extrato de folhas a $100^{\circ} \mathrm{C}$, extrato de folhas a $25^{\circ} \mathrm{C}$, EC - extrato de cascas a $100^{\circ} \mathrm{C}$, extrato de cascas a $25^{\circ} \mathrm{C}$, e água destilada) e quatro repetições de 25 sementes de alface. Em cada parcela experimental (caixa tipo gerbox) foram colocados 8 a $10 \mathrm{~mL}$ do extrato bruto sobre papel substrato mata-borrão, com auxilio de uma seringa, previamente esterilizada em estufa a $105 \pm 3{ }^{\circ} \mathrm{C}$. Em seguida as sementes foram distribuídas uniformemente sobre o papel filtro. As caixas gerbox foram acondicionadas em câmera tipo BOD (modelo $347 \mathrm{CD}$, marca FANEN) com temperatura de $25^{\circ} \mathrm{C}$ e fotoperíodo de $12 \mathrm{~h}$, durante sete dias.

No segundo experimento os extratos de folhas e cascas de juazeiro extraídos na temperatura de $100^{\circ} \mathrm{C} \mathrm{e}$ $25^{\circ} \mathrm{C}$ foram diluídos em água para se obter as diversas concentrações. Estes extratos passaram por um tempo de armazenagem de dois meses e oito dias em recipientes vedados de polietileno sob condições de temperatura 7-10 ${ }^{\circ} \mathrm{C}$ e em constante exposição à luz fluorescente. Antes da realização do ensaio os extratos foram submetidos à análise físico-químico com a finalidade de averiguar se houve ou não oscilações de $\mathrm{pH}$ e $\mathrm{PO}$, possivelmente ocasionadas pelo tempo de armazenamento. 
Foram feitas as diluições de $25 \%, 50 \%$ e $75 \%$ de cada extrato puro que juntamente com o extrato bruto e a água destilada constituíram os tratamentos em cada ensaio. Com isso, cada extrato com suas respectivas concentrações formaram um ensaio, totalizando quatro bioensaios: extrato de folhas a $100{ }^{\circ} \mathrm{C}$ e $25^{\circ} \mathrm{C}$ e extrato de cascas a $100^{\circ} \mathrm{C}$ e 25 ${ }^{\circ} \mathrm{C}$ com diferentes concentrações.

As variáveis analisadas foram porcentagem de germinação, porcentagem de plântulas normais, anormais e mortas, comprimento da raiz (distância em $\mathrm{mm}$ do colo até o ápice meristemático) e da parte aérea (distância em $\mathrm{mm}$ do colo até o ápice) e índice de velocidade de germinação (IVG) que foi calculado de acordo com Maguirre (1962) pela fórmula IVG $=G_{1} / N_{1}+G_{2} / N_{2}+\ldots+G_{n} / N_{n}$; em que: $G_{1}$, $\mathrm{G}_{2}, \mathrm{G}_{\mathrm{n}}=$ número de sementes germinadas computadas na primeira, na segunda e na última contagem; e $\mathrm{N}_{1}, \mathrm{~N}_{2}, \mathrm{~N}_{\mathrm{n}}=$ número de dias da semeadura à primeira, segunda e última contagem. A medição da parte aérea e da raiz de todas as plântulas normais foi feita com auxílio de um paquímetro digital devidamente regulado em $\mathrm{mm}$.

O critério para avaliar a germinação das sementes baseou-se no conceito de germinação fisiológica citada por Marcos Filho (2005), que aponta o inicio da germinação com a embebição da semente e seu final com a protusão da radícula. A contagem de sementes germinadas foi realizada a cada 12 horas. A avaliação das plântulas ocorreu no sétimo dia após a semeadura, classificando-as em normais ou anormais, segundo critérios descritos em Brasil (2009).

O delineamento experimental do segundo experimento foi o inteiramente casualizado com cinco tratamentos $(0,25$, 50,75 e $100 \%$ de concentração do extrato bruto) e quatro repetições com 20 sementes de alface. Em cada parcela experimental (caixa tipo gerbox) foi colocado com auxilio de uma seringa 8 a $10 \mathrm{~mL}$ do extrato sobre o papel substrato mata-borrão, previamente esterilizada em estufa a $105 \pm 3{ }^{\circ} \mathrm{C}$ e em seguida as sementes foram distribuídas uniformemente sobre o papel filtro. As caixas gerbox devidamente esterilizadas foram acondicionadas em câmera tipo BOD com temperatura de $25^{\circ} \mathrm{C}$ e fotoperíodo de $12 \mathrm{~h}$, durante sete dias.

As variáveis obtidas em percentagem foram transformadas em raiz da variável $+0,5$ antes da análise de variância efetuada pelo programa estatístico Sisvar (Ferreira 2003). A comparação das médias foi feita através do teste Scott Knott a $5 \%$ de probabilidade.

\section{Resultados e discussão}

Os extratos de juazeiro estão dentro dos valores normais de potencial osmótico e $\mathrm{pH}$, não sendo, portanto estes fatores responsáveis por possíveis alterações no comportamento germinativo de alface (Tabelas 1 e 2). Sabe-se que em condições normais o $\mathrm{pH}$ deve estar compreendido entre quatro e sete e o potencial osmótico (MPa), abaixo de -0,2. Gatti et al. (2004) recomendam que o potencial osmótico de extratos envolvendo testes de germinação não ultrapasse valores - $0,2 \mathrm{Mpa}$, pois os extratos aquosos podem apresentar determinados solutos que podem alterar a propriedade da água, resultando numa pressão osmótica diferente de zero na solução (Villela et al., 1991). Laynez Garsaball \& Mendez-Natera (2006) apontam os valores de $\mathrm{pH}$ entre 6,0 e 7,5 como os ideais para a germinação da maioria das espécies vegetais.

$\mathrm{Na}$ Tabela 3 observa-se que nenhum dos extratos brutos de folhas e cascas de juazeiro extraídos a $100{ }^{\circ} \mathrm{C}$ e $25^{\circ} \mathrm{C}$ afetou a percentagem de germinação. Porém, o índice de velocidade de germinação (IVG) foi reduzido na presença dos mesmos, apresentando valores inferiores à testemunha. Efeitos sobre outras variáveis e não diretamente sobre a germinação foram observados em outros estudos. Os extratos das casas de troncos e das raízes de canela-sassafrás inibiram o desenvolvimento do sistema radicular das plântulas de sorgo e sua parte aérea teve o crescimento estimulado pelo extrato de casca de raízes. Os extratos de folhas e de cascas de tronco induziram o aumento da biomassa fresca do sistema radicular e a diminuição do teor de clorofila (Carmo et al., 2007). Avaliando também um possível efeito alelopático de folhas, Borella \& Pastorine (2009) observaram que o processo germinativo (porcentagem e a velocidade de germinação) de sementes de tomate e picão-preto foi afetado significativamente pelos extratos de umbu.

A atividade alelopática dos extratos tornou-se mais evidente no desenvolvimento inicial da espécie teste, onde comprometeu bastante seu processo de crescimento e diferenciação. Esta intervenção é mostrada pelos baixos índices de normalidade e elevada percentagem de anormalidade (atrofiamento da raiz, queima e escurecimento da radícola, encurvamento do caulículo, geotropismo negativo, etc.), redução no comprimento de parte aérea e raiz comparada à testemunha.

No entanto, observou-se que o extrato de casca, extraído na temperatura de $100^{\circ} \mathrm{C}$ apresentou efeito negativo baixo, comparado aos demais extratos, pois mesmo apresentando plântulas com menores comprimentos de radícula e baixo índice de velocidade de germinação, não diferiu estatisticamente da testemunha nas demais variáveis analisadas. Por essa razão, é importante ressaltar as diferenças observadas entre a extração feita a frio e a quente, considerando-se os resultados dos bioensaios, pois mesmo não sendo uma técnica sugerida, o preparo de extratos com água quente é muito usado visando uma maior extração e a obtenção de substâncias menos solúveis da planta (Aqüila et al., 1999; Aqüila 2000; Rodrigues 2002).

Avaliando-se os quatro ensaios de juazeiro. Pode-se dizer que a germinação de alface nas diferentes concentrações dos extratos de folhas e cascas de juazeiro não foi afetada sendo sempre superior a $90 \%$ (Tabela 4).

Os extratos de folhas $\left(25^{\circ} \mathrm{C}\right.$ e $\left.100{ }^{\circ} \mathrm{C}\right)$ e o extrato de cascas $\left(100{ }^{\circ} \mathrm{C}\right)$ nas maiores concentrações apresentaram os menores porcentuais de plântulas normais, e na temperatura de extração a $100{ }^{\circ} \mathrm{C}$ as concentrações mais altas dos 
Tabela 1. Características físico-químicas dos extratos aquosos de folhas e retidoma de juazeiro extraídos a $25^{\circ} \mathrm{C}$ e $100^{\circ} \mathrm{C}$ utilizados nos bioensaios para avaliação do potencial alelopático sobre sementes de alface. PO: potencial osmótico; CE: condutividade elétrica e pH.

\begin{tabular}{|c|c|c|c|}
\hline Tratamento & $\mathrm{pH}$ & $\mathrm{CE}(\mathrm{ms} / \mathrm{cm})$ & $\mathrm{PO}(\mathrm{MPa})$ \\
\hline Folhas de juazeiro $\left(100^{\circ} \mathrm{C}\right)$ & 6,5 & 2,56 & $-0,093$ \\
\hline Folhas de juazeiro $\left(25^{\circ} \mathrm{C}\right)$ & 7,07 & 2,15 & $-0,078$ \\
\hline Retidoma de juazeiro $\left(100^{\circ} \mathrm{C}\right)$ & 6,09 & 2,05 & $-0,075$ \\
\hline Retidoma de juazeiro $\left(25^{\circ} \mathrm{C}\right)$ & 6,69 & 2,23 & $-0,081$ \\
\hline Testemunha & 8,07 & 0,23 & $-0,020$ \\
\hline
\end{tabular}

Tabela 2. Características físico-químicas dos extratos aquosos de folhas e retidoma de juazeiro com diluições (extraídos a $25^{\circ} \mathrm{C}$ e $100^{\circ} \mathrm{C}$ ) utilizados nos bioensaios para avaliação do potencial alelopático sobre sementes de alface. PO: potencial osmótico; CE: condutividade elétrica e pH.

\begin{tabular}{|c|c|c|c|}
\hline Tratamento & $\mathrm{PH}$ & $\mathrm{CE}(\mathrm{ms} / \mathrm{cm})$ & PO (MPa) \\
\hline \multicolumn{4}{|c|}{ Folhas de juazeiro $\left(100^{\circ} \mathrm{C}\right)$} \\
\hline $25 \%$ & 6,8 & 0,94 & $-0,034$ \\
\hline $50 \%$ & 6,56 & 1,79 & $-0,065$ \\
\hline $75 \%$ & 6,49 & 2,39 & $-0,087$ \\
\hline $100 \%$ & 6,5 & 2,56 & $-0,093$ \\
\hline Testemunha & 8,07 & 0,23 & $-0,020$ \\
\hline \multicolumn{4}{|c|}{ Folhas de juazeiro $\left(25^{\circ} \mathrm{C}\right)$} \\
\hline $25 \%$ & 6,86 & 0,75 & $-0,027$ \\
\hline $50 \%$ & 7,01 & 1,34 & $-0,049$ \\
\hline $75 \%$ & 7,18 & 1,97 & $-0,072$ \\
\hline $100 \%$ & 7,07 & 2,15 & $-0,078$ \\
\hline Testemunha & 8,07 & 0,23 & $-0,020$ \\
\hline \multicolumn{4}{|c|}{ Retidoma de juazeiro $\left(100^{\circ} \mathrm{C}\right)$} \\
\hline $25 \%$ & 6,27 & 0,57 & $-0,021$ \\
\hline $50 \%$ & 6,05 & 1,25 & $-0,046$ \\
\hline $75 \%$ & 6,04 & 1,72 & $-0,063$ \\
\hline $100 \%$ & 6,09 & 2,05 & $-0,075$ \\
\hline Testemunha & 8,07 & 0,23 & $-0,020$ \\
\hline \multicolumn{4}{|c|}{ Retidoma de juazeiro $\left(25^{\circ} \mathrm{C}\right)$} \\
\hline $25 \%$ & 6,54 & 0,72 & $-0,026$ \\
\hline $50 \%$ & 6,74 & 1,23 & $-0,045$ \\
\hline $75 \%$ & 6,81 & 1,92 & $-0,070$ \\
\hline $100 \%$ & 6,69 & 2,23 & $-0,081$ \\
\hline Testemunha & 8,07 & 0,23 & $-0,020$ \\
\hline
\end{tabular}

Tabela 3. Germinação e crescimento de plântulas de alface (Lactuca sativa L.) em extratos folhas e retidoma de juazeiro (Ziziphus joazeiro Mart.). 2009. PG=Porcentagem de germinação; $\mathrm{PN}=$ Porcentagem de plântulas normais; $\mathrm{PA}=$ Porcentagem de plântulas anormais; $\mathrm{PM}=$ Porcentagem de plântulas mortas; IVG= Índice de Velocidade de Germinação; $C A=$ Comprimento da parte aérea da plântula; $C R=$ Comprimento da raiz da plântula.

\begin{tabular}{|c|c|c|c|c|c|c|c|}
\hline Extratos & PG & PN & PA & PM & IVG & $\mathrm{CA}(\mathrm{mm})$ & $\mathrm{CR}(\mathrm{mm})$ \\
\hline Folhas $\left(100^{\circ} \mathrm{C}\right)$ & $97 \mathrm{a}$ & $59 \mathrm{~b}$ & $37 \mathrm{a}$ & $4 \mathrm{~b}$ & $0,7 \mathrm{~b}$ & $11,8 \mathrm{~b}$ & $11,6 \mathrm{c}$ \\
\hline Folhas $\left(25^{\circ} \mathrm{C}\right)$ & $96 \mathrm{a}$ & $67 \mathrm{~b}$ & $22 \mathrm{~b}$ & $11 \mathrm{a}$ & $0,7 \mathrm{~b}$ & $11,6 \mathrm{~b}$ & $6,7 \mathrm{~d}$ \\
\hline Retidoma $\left(100^{\circ} \mathrm{C}\right)$ & $99 \mathrm{a}$ & $93 \mathrm{a}$ & $4 \mathrm{c}$ & $3 \mathrm{~b}$ & $0,8 \mathrm{~b}$ & $22,8 \mathrm{a}$ & $25,8 \mathrm{~b}$ \\
\hline Retidoma $\left(25^{\circ} \mathrm{C}\right)$ & $99 \mathrm{a}$ & $62 \mathrm{~b}$ & $35 \mathrm{a}$ & $12 \mathrm{a}$ & $0,8 \mathrm{~b}$ & $11,4 \mathrm{~b}$ & $13,7 \mathrm{c}$ \\
\hline Testemunha & $100 \mathrm{a}$ & $98 \mathrm{a}$ & $2 c$ & $0 \mathrm{~b}$ & $1,5 \mathrm{a}$ & $21,2 \mathrm{a}$ & $42,4 \mathrm{a}$ \\
\hline $\mathrm{CV}(\%)$ & 11,2 & 14,5 & 19,7 & 18,9 & 18,5 & 14,6 & 13,7 \\
\hline
\end{tabular}

Médias seguidas da mesma letra, nas colunas, não diferem entre si pelo teste Scott Knott ao nível de 5 \% de significância. 
Tabela 4. Germinação e crescimento de plântulas de alface (Lactuca sativa L.) em extratos de folhas e retidoma de juazeiro (Ziziphus joazeiro Mart.) em diversas concentrações. $\mathrm{PG}=$ Porcentagem de germinação; $\mathrm{PN}=$ Porcentagem de plântulas normais; $\mathrm{PA}=$ Porcentagem de plântulas anormais; $\mathrm{PM}=$ Porcentagem de plântulas mortas; IVG= Índice de Velocidade de Germinação; $C A=$ Comprimento da parte aérea da plântula; CR= Comprimento da raiz da plântula.

\begin{tabular}{|c|c|c|c|c|c|c|c|}
\hline Doses dos extratos & PG & $\mathrm{PN}$ & PA & $\mathrm{PM}$ & IVG & $\mathrm{CA}(\mathrm{mm})$ & $\mathrm{CR}(\mathrm{mm})$ \\
\hline \multicolumn{8}{|c|}{ Folhas de juazeiro $\left(100^{\circ} \mathrm{C}\right)$} \\
\hline $25 \%$ & $95 \mathrm{a}$ & $59 \mathrm{~b}$ & $27 \mathrm{~b}$ & $9 \mathrm{a}$ & $1,24 \mathrm{a}$ & $20,8 \mathrm{a}$ & $19,7 \mathrm{~b}$ \\
\hline $50 \%$ & $100 \mathrm{a}$ & $3 c$ & $96 \mathrm{a}$ & $1 \mathrm{~b}$ & $1,35 \mathrm{a}$ & $11,8 \mathrm{~b}$ & $7,6 \mathrm{c}$ \\
\hline $75 \%$ & $100 \mathrm{a}$ & $1 \mathrm{c}$ & $90 \mathrm{a}$ & $9 \mathrm{a}$ & $0,96 b$ & $3,6 \mathrm{c}$ & $4,8 \mathrm{c}$ \\
\hline $100 \%$ & $90 \mathrm{a}$ & $0 \mathrm{c}$ & $89 a$ & $1 \mathrm{~b}$ & $0,57 \mathrm{c}$ & $0 \mathrm{c}$ & $0 \mathrm{c}$ \\
\hline Testemunha & $99 \mathrm{a}$ & $95 \mathrm{a}$ & $4 \mathrm{c}$ & $0 \mathrm{~b}$ & $1,52 \mathrm{a}$ & $21,7 \mathrm{a}$ & $27,6 \mathrm{a}$ \\
\hline $\mathrm{CV}(\%)$ & 11,2 & 24,5 & 19,7 & 18,9 & 18,5 & 14,6 & 13,7 \\
\hline \multicolumn{8}{|c|}{ Folhas de juazeiro $\left(25^{\circ} \mathrm{C}\right)$} \\
\hline $25 \%$ & $96 \mathrm{a}$ & $16 \mathrm{~d}$ & $74 \mathrm{a}$ & $6 \mathrm{a}$ & $1,41 \mathrm{a}$ & $13,9 \mathrm{~b}$ & $11,5 \mathrm{~b}$ \\
\hline $50 \%$ & $96 \mathrm{a}$ & $61 \mathrm{~b}$ & $27 \mathrm{c}$ & $8 \mathrm{a}$ & $1,15 b$ & $20,2 \mathrm{a}$ & $10,9 \mathrm{~b}$ \\
\hline $75 \%$ & $92 \mathrm{a}$ & $32 c$ & $55 \mathrm{~b}$ & $5 \mathrm{a}$ & $1,03 b$ & $15,4 \mathrm{~b}$ & $10,9 \mathrm{~b}$ \\
\hline $100 \%$ & $95 \mathrm{a}$ & $27 \mathrm{c}$ & $66 \mathrm{a}$ & $2 \mathrm{a}$ & $0,90 \mathrm{~b}$ & $15,1 \mathrm{~b}$ & $10,8 \mathrm{~b}$ \\
\hline Testemunha & $99 \mathrm{a}$ & $95 \mathrm{a}$ & $4 \mathrm{~d}$ & $0 \mathrm{a}$ & $1,52 \mathrm{a}$ & $21,7 \mathrm{a}$ & $27,6 \mathrm{a}$ \\
\hline $\mathrm{CV}(\%)$ & 12,8 & 20,4 & 19,9 & 18,2 & 14,2 & 15,8 & 16,4 \\
\hline \multicolumn{8}{|c|}{ Retidoma de juazeiro $\left(100^{\circ} \mathrm{C}\right)$} \\
\hline $25 \%$ & $100 \mathrm{a}$ & $87 \mathrm{a}$ & $11 \mathrm{~b}$ & $2 \mathrm{a}$ & $1,47 \mathrm{a}$ & $19,9 \mathrm{a}$ & $30,9 \mathrm{a}$ \\
\hline $50 \%$ & $97 \mathrm{a}$ & $73 \mathrm{~b}$ & $22 \mathrm{a}$ & $2 \mathrm{a}$ & $1,38 \mathrm{a}$ & $14,3 \mathrm{~b}$ & $31,1 \mathrm{a}$ \\
\hline $75 \%$ & $99 \mathrm{a}$ & $84 \mathrm{~b}$ & $10 \mathrm{~b}$ & $5 \mathrm{a}$ & $1,32 \mathrm{a}$ & $12,0 \mathrm{bc}$ & $17,9 \mathrm{~b}$ \\
\hline $100 \%$ & $99 \mathrm{a}$ & $63 \mathrm{~b}$ & $30 \mathrm{a}$ & $6 \mathrm{a}$ & $1,27 \mathrm{a}$ & $9,0 \mathrm{c}$ & $8,5 \mathrm{c}$ \\
\hline Testemunha & $99 \mathrm{a}$ & $95 \mathrm{a}$ & $4 \mathrm{~d}$ & $0 \mathrm{a}$ & $1,52 \mathrm{a}$ & $21,7 \mathrm{a}$ & $27,6 \mathrm{a}$ \\
\hline $\mathrm{CV}(\%)$ & 12,2 & 13,7 & 20,5 & 19,8 & 14,3 & 15,4 & 16,3 \\
\hline \multicolumn{8}{|c|}{ Retidoma de juazeiro $\left(25^{\circ} \mathrm{C}\right)$} \\
\hline $25 \%$ & $99 \mathrm{a}$ & $96 \mathrm{a}$ & $0 \mathrm{a}$ & $3 \mathrm{a}$ & $1,53 \mathrm{a}$ & $17,2 \mathrm{~b}$ & $24,3 \mathrm{~b}$ \\
\hline $50 \%$ & $100 \mathrm{a}$ & $91 \mathrm{a}$ & $4 \mathrm{a}$ & $5 \mathrm{a}$ & $1,50 \mathrm{a}$ & $24,1 \mathrm{a}$ & $25,2 \mathrm{~b}$ \\
\hline $75 \%$ & $100 \mathrm{a}$ & $96 \mathrm{a}$ & $2 \mathrm{a}$ & $2 \mathrm{a}$ & $1,46 \mathrm{a}$ & $10,7 \mathrm{c}$ & $19,8 \mathrm{c}$ \\
\hline $100 \%$ & $97 \mathrm{a}$ & $91 \mathrm{a}$ & $4 \mathrm{a}$ & $2 \mathrm{a}$ & $1,40 \mathrm{a}$ & $10,1 \mathrm{c}$ & $17,6 \mathrm{c}$ \\
\hline Testemunha & $99 \mathrm{a}$ & $95 \mathrm{a}$ & $4 \mathrm{a}$ & $0 \mathrm{a}$ & $1,52 \mathrm{a}$ & $21,7 \mathrm{a}$ & $27,6 \mathrm{a}$ \\
\hline $\mathrm{CV}(\%)$ & 12,5 & 15,2 & 25,7 & 26,5 & 13,3 & 15,5 & 12,5 \\
\hline
\end{tabular}

Médias seguidas da mesma letra, nas colunas, não diferem entre si pelo teste Scott Knott ao nível de 5 \% de significância.

extratos produziram os maiores índices de anormalidade. A porcentagem de plântulas mortas foi baixa (Tabela 4).

O índice de velocidade de germinação (IVG) foi reduzido nas maiores concentrações dos extratos obtidos de folhas, independente da temperatura de extração. Estes dados confirmam que muitas vezes, o efeito alelopático não se dá pela germinabilidade, mas sobre a velocidade de germinação ou sobre outra variável do processo, provocando alterações na curva de distribuição de germinação ou no padrão poli modal de distribuição de germinação das sementes devido ao ruído informacional, isto é, interferências ambientais que bloqueiam ou retardam o andamento de processos metabólicos (Ferreira \& Borghetti 2004).

Os processos de formação de parte aérea e raiz de plântulas de alface sofreram influencia negativa quando sob ação do extrato de cascas e folhas de juazeiro $\left(25^{\circ} \mathrm{C}\right.$ e $\left.100^{\circ} \mathrm{C}\right)$ nas maiores concentrações. Produzindo os menores comprimentos caulículo e radícula. Isso demonstra que no geral as menores concentrações não têm efeito fitotóxico para essa espécie e que sua ação só se manifesta nas concentrações mais altas. Esses resultados são corroborados por Hoffmann et al. (2007) onde o mesmo percebeu que ocorria redução no comprimento das raízes de picão preto e alface com o aumento na concentração dos extratos aquosos de folhas de espirradeira.

Observou-se que na ausência dos extratos de folhas, independente da temperatura de extração as sementes de alface se aproximavam de $90 \%$ de germinação após 12 h de semeadura. Enquanto isso, nas maiores concentrações dos extratos das folhas a germinação não chegava nem a 50\%. Esta redução no tempo de germinação foi ainda maior quando se aplicou a temperatura de extração a $25^{\circ} \mathrm{C}$, pois nela houve uma acentuada disparidade no padrão germinativo comparado a testemunha.

Os efeitos alelopáticos podem ser observados tanto sobre a germinação quanto sobre o crescimento da plântula. Ferreira \& Aquila (2000) apontam que a germinação é menos sensível aos aleloquímicos do que o crescimento da plântula, pois as substâncias alelopáticas podem induzir o aparecimen- 
to de plântulas anormais, sendo a necrose da radícula um dos sintomas mais comuns. Hagemann et al. (2010) verificaram que o uso de extratos da parte aérea de Avena sativa e Avena strigosa provoca redução na germinabilidade e no crescimento da radícula e do hipocótilo de Lolium multiflorum e Euphorbia heterophylla. Silva et al. (2006) avaliando uma possível atividade alelopática de extrato aquoso de cascas de Amburana cearensis observaram a presença de compostos ativos que provocaram inibição na porcentagem inicial e final da germinação das sementes de sorgo.

O efeito mais drástico sobre o crescimento do que a germinação foi também encontrada por Mazzafera (2003) em Syzygium aromaticum, Periotto et al. (2004) em Andira humilis e Carmo et al. (2007) em Ocotea odorifera.

As saponinas podem ser responsáveis pelos resultados observados no presente trabalho. Os efeitos alelopáticos verificados no presente trabalho podem ser também uma explicação para a ausência de plântulas próximas as árvores mãe, sendo necessários mais estudos para determinar a natureza dos aleloquímicos.

\section{Conclusão}

Os extratos brutos e diluídos de $Z$. joazeiro não afetam o percentual de germinação, no entanto os extratos brutos das folhas e das cascas apresentaram efeito sobre a velocidade de germinação, demonstrando assim o efeito fitotóxico sobre a germinação das sementes de L. sativa. Nas maiores concentrações dos extratos foi observada elevada porcentagem de plântulas anormais. Extratos diluídos de folhas e de cascas reduziram o crescimento da raiz e parte aérea de L. sativa.

\section{Agradecimentos}

Ao CNPq pela concessão da Bolsa de produtividade a segunda autora.

\section{Referencias bibliográficas}

Aqüila, M.E.A. 2000. Efeito alelopático de Ilex paraguariensis A. St.-Hil. na germinação e crescimento inicial de Lactuca sativa L. Iheringia, Série Botânica 53: 51-66.

Aqüila, M.E.A.; Ungaretti, J.A.C. \& Michelin, A. 1999. Preliminary observation on allelopathic activity in Achyrocline satureoides (Lam.) DC. Acta Horticulture 502: 383-388.

Ayers, R.S. \& Westcot, D.W. 1976. Water quality for agriculture. Rome, FAO. (FAO. Irrigation and Drainage Paper, 29).

Borella, J. \& Pastorini, L.H. 2009. Influência alelopática de Phytolacca dioica L. na germinação e crescimento inicial de tomate e picão-preto. Revista Biotemas 22(3): 67-75.

BRASIL. Ministério da Agricultura. 2009. Regras para Análise de Sementes. Brasília, Ministério da Agricultura.

Carmo, F.M.S.; Borges, E.E.L \& Takaki, M. 2007. Alelopatia de extratos aquosos de canela-sassafrás (Ocotea odorifera (Vell.) Rohwer) Acta Botanica Brasilica 21: 697-705.
Ferreira, A.G. \& Áquila, M.E.A. 2000. Alelopatia: uma área emergente da ecofisiologia. Revista Brasileira de Fisiologia Vegetal 12 (edição especial): 175-204.

Ferreira, A.G. \& Borguetti, F. 2004. Germinação: do básico ao aplicado Porto Alegre, Artmed.

Ferreira, D.F. 2003. Programa de análises estatísticas (Statistical Analysis Software) e planejamento de experimentos. Lavras, Universidade Federal de Lavras. Versão 4.3

Gatti, A.B.; Perez, S.C.J.G. \& Lima, M.I.S. 2004. Efeito alelopático de Aristolochia esperanzae O. Kuntze na germinação e no crescimento de Lactuca sativa L. e Raphanus sativus L. Acta Botanica Brasilica 8(3): 459-472.

Gusman, G.S.; Bittencourt, A. H.C. \& Vestena, S. 2008 Alelopatia de Baccharis dracunculifolia DC. sobre a germinação e desenvolvimento de espécies cultivadas. Acta Scientiarum 30: 119-125.

Hagemann, T.R.; Benin, G.; Lemes, C.; Marchese, J.A.; Martin, T.N.; Pagliosa, E.S. \& Beche, E. 2010. Potencial alelopático de extratos aquosos foliares de aveia sobre azevém e amendoim-bravo. Bragantia 69(3): 509-518.

Hoffmann, C.E.F.; Neves, L.A.S.; Bastos, C.F. \& Wallau, G. 2007. Atividade alelopática de Nerium Oleander L. e Dieffenbachia picta schott em sementes de Lactuca Sativa L. e Bidens pilosa L. Revista de Ciências Agroveterinárias 6(1): 11-21.

Laynez-Garsaball, J.A. \& Mendez-Natera, J.R. 2006. Efectos de extractos acuosos del follaje del corocillo (Cyperus rotundus L.) sobre la germinación de semillas y el crecimiento de plântulas de ajonjolí (Sesamum indicum L.) CV. Idesia 24(2): 61-75.

Leite, D.S. \& Oliveira, S.C.C. 2007. Efeito de Folhas de Solanum lycocarpum St. A.Hil. e a Influência de Diferentes Matrizes e Idade das Folhas no Crescimento de Sesamum indicum L. Revista Brasileira de Biociências 5: 1083-1085.

Lorenzi, H. \& Matos, F.J.A. 2008. Plantas medicinais no Brasil: nativas e exóticas. 2 ed. Nova Odessa, Instituto Plantarum.

Lorenzi, H.E. 2009. Árvores brasileiras: manual de identificação e cultivo de plantas arbóreas nativas do Brasil. 5. ed., v.1. Nova Odessa, Instituto Plantarum.

Maguire, J.D. 1962. Speed of germination-aid in selection and evaluation for seedling emergence and vigour. Crop Science 2(1):176-177.

Maraschin-Silva, F. \& Áquila, M.E.A. 2005. Potencial alelopático de Dodonaea viscosa (L.) Jacq. Iheringia 60: 91-98

Maraschin-Silva, F. \& Aquila, M.E.A. 2006, Contribuição ao estudo do potencial alelopático de espécies nativas. Revista Árvore 30: 547-555

Marcos Filho, J. 2005. Fisiologia de sementes de plantas cultivadas. Piracicaba, FEALQ.

Mazzafera, P. 2003. Efeito alelopático do extrato alcoólico do cravo-da-índia e eugenol. Revista Brasileira de Botânica 26(2): 231-238.

Oliveira, A.K.; Diógenes, F.E.P.; Coelho, M.F.B. \& Maia, S.S.S. 2009. Alelopatia em extratos de frutos de juazeiro (Ziziphus joazeiro Mart. - Rhamnaceae). Acta Botanica Brasilica 23(4): 1186-1189.

Periotto, F.; Perez, S.C.J.G.A. \& Lima, M.I.S. 2004. Efeito alelopático de Andira humilis Mart. ex Benth. na germinação e no crescimento de Lactuca sativa L. e Raphanus sativus L. Acta Botanica Brasilica 18(3): 425-430.

Rodrigues, K.C.S. 2002. Verificação da atividade alelopática de Myrciaria cuspidata Berg. (Camboim). 78f. Dissertação de Mestrado em Botânica. Instituto de Biociências, Porto Alegre.

Silva, W.A.; Nobre, A.P.; Leites. A.P.; Silva, M.S.C.; Lucas, R.C. \& Rodrigues, O.G. 2006. Efeito alelopático de extrato aquoso de Amburana cearensis A. Smith na germinação e crescimento de sementes de sorgo (Sorghum bicolor L.). Agropecuária Científica no Semi-árido 2(1): 48-54.

Souza, S.A.M.; Cattelan, L.V.; Vargas, D.P.; Piana, C.F.B.;Vera Lucia Bobrowski, V.L. \& Rocha, B.H.G. 2005. Atividade alelopática e citotóxica do extrato aquoso de espinheira-santa (Maytenus ilicifolia Mart. Ex Reiss). UEPG - Ciências Biológicas e da Saúde 11(3/4): 7-14.

Vilela, F.A.; Doni Filho, L. \& Sequeira, E.L. 1991. Tabela de potencial osmótico em função da concentração de polietileno glicol $6000 \mathrm{e}$ da temperatura. Pesquisa Agropecuária Brasileira 26: 1957-1968. 